\title{
Mixed Carbon Policies Based on Cooperation of Carbon Emission Reduction in Supply Chain
}

\author{
Yongwei Cheng, ${ }^{1,2}$ Dong Mu, ${ }^{1}$ and Yi Zhang' \\ ${ }^{1}$ School of Economics and Management, Beijing Jiaotong University, Beijing 100044, China \\ ${ }^{2}$ Academy of Modern Logistics Industry, Beijing Wuzi University, Beijing 101149, China \\ Correspondence should be addressed to Yongwei Cheng; chehan1986@126.com
}

Received 2 October 2016; Accepted 28 November 2016; Published 12 January 2017

Academic Editor: Paolo Renna

Copyright (C) 2017 Yongwei Cheng et al. This is an open access article distributed under the Creative Commons Attribution License, which permits unrestricted use, distribution, and reproduction in any medium, provided the original work is properly cited.

\begin{abstract}
This paper established cooperation decision model for a mixed carbon policy of carbon trading-carbon tax (environmental tax) in a two-stage $S$ - $M$ supply chain. For three different cooperative abatement situations, we considered the supplier driven model, the manufacturer driven model, and the equilibrium game model. We investigated the influence of mixed carbon policy with constraint of reduction targets on supply chain price, productivity, profits, carbon emissions reduction rate, and so on. The results showed that (1) high-strength carbon policies do not necessarily encourage enterprises to effectively reduce emissions, and increasing market acceptance of low carbon products or raising the price of carbon quota can promote the benign reduction; (2) perfect competitive carbon market has a higher carbon reduction efficiency than oligarch carbon market, but their optimal level of cooperation is the same and the realized reduction rate is in line with the intensity of carbon policy; (3) the policy sensitivity of the carbon trading mechanism is stronger than the carbon tax; "paid quota mechanism" can subsidize the cost of abatement and improve reduction initiative. Finally, we use a numerical example to solve the optimal decisions under different market situations, validating the effectiveness of model and the conclusions.
\end{abstract}

\section{Introduction}

With rapid development of economy, China is suffering from energy shortages and environmental pollution. The outbreak of large-scale "smoggy weather" has caught the attention of the public. "U.S.-China Joint Announcement on Climate Change" is released in November 2014. China intends to achieve the peaking of $\mathrm{CO}_{2}$ emissions around 2030 and to make best efforts to peak early. In response to the severe global climate change and a wide range of emission reduction agreement, China is committed to accelerating the development of carbon emission reduction and a low-carbon economy.

Chinese National Development and Reform Commission issued "National Climate Change Program" in 2007. And the State Council proposed the target that we would reduce carbon dioxide emissions per unit of GDP in 2020 by $40-45$ percent over 2005. Later, in 2012, seven provinces and cities like Beijing, Shanghai, Guangdong, and so on take the lead in putting out a trial use of carbon emission trading. Until
October 2015, the seven carbon trading pilot provinces had achieved a total of 13.75 million tons of carbon dioxide, cumulative turnover of over 500 million yuan, and 15.21 million tons of total volume of carbon trading quotas auction and received a total auction income of 760 million yuan. At the same time, China's National Development and Reform Commission, Ministry of Finance, and other departments jointly issued the "Special Report of China Carbon Tax Framework Design Tax" to recommend the early introduction of a carbon tax. In fact, the recent increase in oil consumption tax has already played the role of carbon tax. In summary, emerging trends of two parallel carbon reduction policy systems, carbon trading and environmental tax, have affected many companies, especially those with high emissions and inefficient energy.

Currently, carbon emission policies adopted worldwide conclude "cap-and-trade" mechanism, "carbon tax," and administrative emission reduction. Compared with other carbon emission policies, "cap-and-trade" mechanism is more efficient and easier to implement and can achieve significant 
savings in public resources [1]. However, Metcalf [2] believes that the "carbon tax" policy is more complete than "capand-trade" mechanism on the implementation process and therefore is more efficient. In fact, if we adopt a generalized definition of "carbon tax" as refined oil consumption tax, import and export of carbon tariffs, and other taxes, the majority of the world countries have already introduced "green tax" system. With the success of Europe Union Emissions Trading System (EUETS), Europe Union Emissions Trading Scheme (UKETS), National Trust of Australia-NSW, pilot carbon markets in China, and other carbon trading markets, coexistence of multiple carbon policies is becoming the trend. However, the hybrid carbon policy has not yet aroused attention in academic research.

Enterprises in carbon trading market are mainly from heavy pollution and high emission industries like steel and power generation. For example, there are 193 companies under emission control in Guangzhou exchange in 2015. Among them, there are 57 steel companies, 64 thermal power enterprises, 11 petrochemical enterprises, and 61 cement companies. The vast majority of these enterprises belong to the supply chain upstream suppliers of raw materials. The government assigns a certain amount of carbon emission quotas to firms yearly. When a firm has carbon emissions less (or more) than its quotas, it can sell extra quotas (or buy additional quotas). There are also few companies like Guangzhou Carbon Emissions Exchange that implement paid quota system. For paid quota system, companies cannot get the full quota but bid a certain percentage of carbon credits (such as carbon deposit paid by the Guangzhou quota ratio of 3\%). Therefore, the implementation of carbon policy would change the production planning and cost structure in these enterprises, and effect along the supply chain is transferred by production, pricing, and other operational decisions.

With the carbon market maturing and increase of consumer awareness for environmental protection, more and more manufacturers are willing to give priority to purchase low-carbon products [3] or even to carry out emission reduction cooperation with the upstream manufacturers [4]. But in reality such cooperation for carbon emissions reduction between enterprises is limited except specific business like acquisitions. It is critical for these companies to choose the appropriate forms of cooperation and the degree of cooperation. At the same time, core business in the supply chain can be either the upstream suppliers or the downstream manufacturers, which may make the implementation efficiency of the effect of carbon policy different. Therefore, considering the structure of the market forces in supply chain business is necessary in this study.

The remainder of this paper is organized as follows. After reviewing related literature in Section 2, in Section 3 we formulate three supply chain models according to different low-carbon policies, compare these models, and discuss the impact of mixed carbon policies on supply chain performance in Section 4. Section 5 conducts numerical experiments to provide more insights. And the conclusion is made in Section 6.

\section{Literature Review}

The paper is closely related to three streams of literature: carbon trading mechanism in operations management, carbon tax (environmental tax) policies in operations management, and comparative analysis of the two carbon policies from the perspective of supply chain. We briefly review the three streams of related literature.

\subsection{Operations Management Based on Carbon Trading} Mechanism. Operational management with low-carbon has become new important decision problem of companies. Fu et al. [5] investigate the strategy of promoting investment in reducing carbon emissions for suppliers and manufacturers in a two-echelon supply chain under a contract with punishment mechanism. Altmann and Bogaschewsky [6] present a robust optimization-based closed-loop supply chain design model with multiobjective. Jaber et al. [7] developed a two-level supply chain inventory model with a coordination mechanism based on the European Union Emissions Trading System (EUETS), providing implications for companies to minimize inventory and carbon emission cost. Diabat et al. [8] introduced a multiechelon multicommodity facility location problem and explored the impact of carbon emissions price on cost and supply chain structure. Xie and Zhao [4] explored interactions between supply chain members, the effect of carbon trading price on carbon reduction efficiency, and a comparison of social welfare and other issues. Chaabane et al. [9] established multiperiod sustainable supply chain MIP models. Du et al. [1] introduce carbon trading into supply chain management and believed that carbon trading policy is more efficient, is easier to implement, and can achieve significant saving in public resources. Kockar et al. [10] studied the effect of carbon trading prices and carbon emission constraints on operations and price in the electricity industry.

\subsection{Operations Management Based on Carbon Tax. Research} on carbon tax gradually penetrated into the microscopic fields of supply chain from the macroeconomic level. Cheng and Xiong [11] studied, respectively, the optimal carbon dioxide emission reductions and pricing strategies for the manufacturer and retailer and the impact of carbon tax rate on carbon dioxide emission reductions and product sale price. Xiong et al. [12] analyzed the impact of carbon taxes and consumer awareness on carbon emission unit of manufacturers and profits along supply chain members with different channel structures. Luo [13] studied such issues as optimal pricing and expected demand of the electric vehicle supply chain based on the government's subsidy and the approach of cooperative game. Sim et al. [14] estimated carbon emissions of four transport modes including land, rail, air, and maritime to develop environment-friendly transport policy for the government. Lin and $\mathrm{Li}[15]$ gave a comprehensive estimate of the emission reduction effect for five Nordic countries. And they found that carbon tax levied in Finland had a significant negative impact on the growth rate of per capita carbon dioxide emissions; and in Denmark, Sweden, and Netherlands the negative impact is not significant; carbon 
tax in Norway is supposed to be ineffective. Li and $\mathrm{Su}$ [16] researched carbon tax policy's influence on the production strategies of upstream and downstream enterprises on the supply chain based on the EOQ model.

\subsection{Comparative Analysis of Carbon Trading and Carbon} Taxes for Supply Chain. There is some literature focus on comparative analysis of carbon policies: the carbon trading policies and carbon tax. Yang et al. [17] studied the misreporting behavior of the supply chain members and their influences on supply chain performance are investigated based on "Benchmarking" carbon quota allocation mechanism. Hoen et al. [18] studied the effect of two carbon policies on the transport mode selection decision. And they concluded that the carbon policies for freight transport are not likely to result in significant changes in transport modes. Yang et al. [19] studied the effect of low-carbon policies on channel coordination for two-stage supply chain. Four different models including the basic model, the carbon emission model, the carbon emission trading model, and the carbon tax model are considered. The results showed that carbon emission trading model is more effective for supply chain on motivation to reduce carbon emissions. Gao and Ryan [20] addressed a double-period, multiperiod, and closed-loop supply chain network design model which was extended with carbon tax and carbon quotas. Choi [21] first constructed a multiperiod procurement planning model for the fashion retailer with risk factors of interest rates, budget, and profit. Then they take the carbon tax and carbon quotas into consideration. Song and Leng [22] established a newsboy model with carbon policy, including carbon quotas, carbon taxes, and carbon trading mechanisms. Benjaafar et al. [23] constructed a cost minimization programming model with carbon emission allowances, taking the fixed-rate carbon tax into consideration. Then they used the models to investigate the impact of collaboration decisions among firms on their costs and carbon emissions.

The above literatures generally consider carbon policy as "exogenous variables" in operational coordination of supply chains and limited research concerned about the level of carbon policy itself in supply chains, such as the optimization of paid quota proportion and carbon tax rate. Most research focused on comparative analysis rather than considering carbon trading and carbon tax (environmental tax) as a parallel carbon policy in decision models. This paper addressed supply chain cooperation for carbon emissions reduction with hybrid carbon policy based on Guangzhou Carbon Exchange and subject to market strength structures.

\section{Preliminaries and Model Descriptions}

3.1. Preliminaries. We consider a single vendor (such as steel), a single manufacturer (such as cars), consumers, and government department supply chain system components. Government can take carbon trading and carbon taxes (environmental tax) individually or simultaneously as the carbon policy with policy intensity $\lambda$ (the proportion of paid quotas or carbon tariff). Supplier invests in manufacturing operations to reduce emissions. The cost of carbon emissions in the supply chain system can be expressed as $(1 / 2) k_{s} \tau^{2}$, where $k_{s}$ is the cost coefficient of carbon reduction and $\tau$ is the realized carbon reduction rate. The manufacturer participates in carbon reduction voluntarily with cooperative efforts $\mu$; the realized carbon reduction rate per product is $\mu \tau$. The cost of carbon emissions reduction can be expressed as $(1 / 2) k_{m}(\mu \tau)^{2}$, where $k_{m}$ is the manufacture's cost coefficient. According to decision-making sequence, it can be divided into "supplier driven model," "manufacturer driven model," and "Nash decision model."

According to carbon trading market rules, under loose carbon policy $(\lambda=0)$, the output of supplier is $Q$, and carbon reduction rate is $e_{s}$. And they do not have to sell or buy carbon quotas or pay carbon tax at carbon price $P_{e}$. Corporations can trade when they have surplus or lack quotas in the carbon emission trading market. The paper takes "paid carbon quotas" mechanism into consideration; the enterprise shall bid with reserve price $\bar{p}_{e s} / \bar{p}_{e m}$ to purchase enough quotas to qualify for the remaining free quota. The greater proportion of paid quota represents the stronger policy, thus requiring the supplier to increase reduction rate per unit of product. The income of government will be used to subsidize the cost of corporate emissions reduction $\Delta K_{s} / \Delta K_{m}$. Let $c$ be the unit production cost of the supplier and it sells products to the retailer with wholesale price $w$. The demand function is $Q=\phi-b p+\beta \tau$, where $\phi$ is the potential market scale, $b$ is the coefficient of price sensitivity, $\beta$ is the consumer preference coefficient for low-carbon products, and $p$ is the retail price. For convenience, the carbon assets of suppliers and manufacturers can be written as $Z_{s}=e_{s} p_{e}$ and $Z_{m}=$ $e_{m} p_{e} ; e_{0}=e_{s}+e_{m}, z_{0}=z_{s}+z_{m}, k_{0}=k_{s}+k_{m}$, and $\bar{k}=k_{s} / k_{m}$.

\subsection{The Description of Models}

3.2.1. Model 1: Supplier Driven Model. The problem is modeled as a Stackelberg game in which the supplier is the leader and the manufacturer is the follower. As a Stackelberg leader, the supplier decides a wholesale price $w$ and the reduction rate $\tau$, and then the retailer decides retail price $P$ and cooperative effort for carbon reduction is $\mu$. The supplier reduces carbon emission with policy intensity $\lambda$ which represents the work for companies to undertake. After reduction, units of carbon emission reduction coefficients of raw materials decrease from $e_{s}$ to $(1-\tau) e_{s}$. Surplus or lack quotas $(\tau-\lambda) e_{s}$ can sell or buy from the carbon emission trading market at price $P_{e}$. Among them, $Z_{s}=$ $e_{s} P_{e}$ is potential carbon asset per unit of product of supplier. Similarly, the surplus or lack quotas of $(\mu \tau-\lambda) e_{m}$ from manufacturers can also be traded in the carbon market. Both sides' benefit functions are as follows:

$$
\begin{aligned}
\pi_{s}= & {\left[w-c+z_{s}(\tau-\lambda)\right](\phi-b p+\beta \tau)-\frac{1}{2} k_{s} \tau^{2}, } \\
\pi_{m}= & {\left[p-w+z_{m}(\mu \tau-\lambda)\right](\phi-b p+\beta \tau) } \\
& -\frac{1}{2} k_{m}(\mu \tau)^{2} .
\end{aligned}
$$


We conduct Stackelberg backward induction of (2) and take the derivative of $\partial \pi_{m} / \partial p=0, \partial \pi_{m} / \partial \mu=0$; we find

$$
\begin{aligned}
& p=\frac{\phi+\beta \tau+b\left[w-z_{m}(\lambda+\mu \tau)\right]}{2 b}, \\
& \mu=\frac{z_{m}(\phi-b p+\beta \tau)}{\tau k_{m}} .
\end{aligned}
$$

Substituting the prices $p$ and cooperative effort $\mu$ given in (3) into the profit function given in (1) and taking the derivative of $\partial \pi_{s} / \partial w=0, \partial \pi_{s} / \partial \tau=0$, we find the profit is maximized at

$$
\begin{aligned}
\mu_{1}^{*}= & \left(\bar{k}-\frac{2 \beta z_{s}}{2 k_{m}-b z_{m}^{2}}\right) \frac{b z_{m}}{\beta+b z_{s}}, \\
\tau_{1}^{*}= & \frac{\left(\beta+b z_{s}\right)\left[\phi-b\left(c+\lambda z_{0}\right)\right]}{4 b k_{s}-\left(\beta+b z_{s}\right)^{2}-2 \bar{k} b^{2} z_{m}^{2}}, \\
p_{1}^{*}= & \frac{\left[\phi-b\left(c+\lambda z_{0}\right)\right]\left[3 k_{s}-z_{s}\left(\beta+b z_{s}\right)-2 \bar{k} b z_{m}^{2}\right]}{4 b k_{s}-\left(\beta+b z_{s}\right)^{2}-2 \bar{k} b^{2} z_{m}^{2}} \\
& +\left(c+\lambda z_{0}\right), \\
w_{1}^{*}= & \frac{\left[\phi-b\left(c+\lambda z_{0}\right)\right]\left[2 k_{s}-z_{s}\left(\beta+b z_{s}\right)-\bar{k} b z_{m}^{2}\right]}{4 b k_{s}-\left(\beta+b z_{s}\right)^{2}-2 \bar{k} b^{2} z_{m}^{2}} \\
& +\left(c+\lambda z_{s}\right), \\
Q_{1}^{*}= & \left(\bar{k}-\frac{2 \beta z_{s}}{2 k_{m}-b z_{m}^{2}}\right) \frac{b k_{m}\left[\phi-b\left(c+\lambda z_{0}\right)\right]}{4 b k_{s}-\left(\beta+b z_{s}\right)^{2}-2 \bar{k} b^{2} z_{m}^{2}} .
\end{aligned}
$$

For the government, carbon policy with high intensity will lay big burden on the business, while lighter carbon policy cannot complete its emission reduction targets. Therefore, a reasonable carbon policy should satisfy the following equation:

$$
\lambda=\tau_{1}^{*}=\frac{\left(\beta+b z_{s}\right)\left[\phi-b\left(c+\lambda z_{0}\right)\right]}{4 b k_{s}-\left(\beta+b z_{s}\right)^{2}-2 \bar{k} b^{2} z_{m}^{2}} .
$$

Then we can get the optimal policy intensity in MSI:

$$
\lambda_{1}^{*}=\frac{\left(\beta+b z_{s}\right)(\phi-b c)}{4 b k_{s}-\left(\beta+b z_{s}\right)\left(\beta-b z_{m}\right)-2 \bar{k} b^{2} z_{m}^{2}} .
$$

When policy intensity $\lambda \in\left[0, \lambda_{1}^{*}\right]$, the supplier can finish the target and they get some income through carbon emissions quota trading with relaxed carbon policy $(\lambda \rightarrow 0)$. However, supplier will fail to finish a given task, and they must pay for the corresponding carbon resource when $\lambda>$ $\lambda_{1}^{*}$. Therefore, $\left(\lambda-\lambda_{1}^{*}\right)$ can be regarded as governmental regulation strategy of carbon policy in MSI.

When the carbon market implements the "paid quota" mechanism, the enterprises shall bid to purchase enough paid quotas. Government would use the revenue to set up a "special fund for carbon emission management" and to ensure the enterprises have the motivation on energy conservation.

If the quota auction income subsidizes the supplier, we can get the equation as follows:

$$
\begin{aligned}
& \frac{\left(\beta+b z_{s}\right)(\phi-b c)}{4 b k_{s}-\left(\beta+b z_{s}\right)^{2}-2 \bar{k} b^{2} z_{m}^{2}} \\
& =\frac{\left(\beta+b z_{s}\right)\left[\phi-b\left(c+\lambda z_{0}\right)\right]}{4 b\left(k_{s}-\Delta k_{s 1}\right)-\left(\beta+b z_{s}\right)^{2}-2\left(\left(k_{s}-\Delta k_{s 1}\right) / k_{m}\right) b^{2} z_{m}^{2}} .
\end{aligned}
$$

The abatement cost subsidy of supplier is $\Delta k_{s 1}^{*}=(\bar{k}-$ $\left.2 \beta z_{s} /\left(2 k_{m}-b z_{m}^{2}\right)\right)\left(\lambda b z_{0} k_{m}^{2} / 2\left(2 k_{m}-b z_{m}^{2}\right) \widehat{Q}_{1}\right)$; among it, $\widehat{Q}_{1}=$ $\eta b k_{m}(\phi-b c) /\left(4 b k_{s}-\left(\beta+b z_{s}\right)^{2}-2 \bar{k} b^{2} z_{m}^{2}\right)$ is the initial production in MSI with loose carbon policy $(\lambda=0)$, where $\eta=\bar{k}-\left(2 \beta z_{s} /\left(2 k_{m}-b z_{m}^{2}\right)\right)$. If there is no income except for the "special fund for carbon emission management," the quota auction income is larger than abatement cost subsidy $\lambda e_{s} \widehat{Q}_{1} \bar{p}_{e s 1} \geq \Delta k_{s 1}^{*}$. Finally, we get the optimal auction reserve price of supplier in MSI

$$
\bar{p}_{e s 1}^{*}=\left(\bar{k}-\frac{2 \beta z_{s}}{2 k_{m}-b z_{m}^{2}}\right) \frac{b k_{m}^{2}\left(1+e_{m} / e_{s}\right)}{2\left(2 k_{m}-b z_{m}^{2}\right) \widehat{Q}_{1}^{2}} p_{e} .
$$

Similarly, if the quota auction income subsidizes the manufacturer, the optimal abatement cost subsidy is $\Delta k_{m 1}^{*}=$ $\eta \lambda z_{0} k_{m}^{2} /\left(\eta \lambda z_{0} k_{m}+2 \bar{k} z_{m}^{2} \widehat{Q}_{1}\right)$. Because $\lambda e_{m} \widehat{Q}_{1} \bar{p}_{e m 1} \geq \Delta k_{m 1}^{*}$, the optimal auction reserve price of manufacturer in MSI is $\bar{p}_{e m 1}^{*}=\left(\eta k_{m}^{2}\left(1+e_{s} / e_{m}\right) /\left(\eta \lambda z_{0} k_{m}+2 \bar{k} z_{m}^{2} \widehat{Q}_{1}\right) \widehat{Q}_{1}\right) p_{e}$.

Particularly, when $\lambda=0, \bar{p}_{e m 1}^{*}=(\eta(1+$ $\left.\left.e_{s} / e_{m}\right) / 2 \bar{k}\left(z_{m} / k_{m}\right)^{2} \widehat{Q}_{1}^{2}\right) p_{e}$.

In fact, it is possible that the government implements carbon tax (environmental tax) policy at the same time, which is the mixing carbon policy for carbon trading and carbon tax. Observing $\tau_{1}^{*}$, if $\lambda$ is considered as the carbon tariff with a tax base of carbon asset value $Z_{0}$, the government can motivate the enterprises to reduce carbon emission by regulating carbon trading price $P_{e}$. The equation is as follows:

$$
\begin{aligned}
& \frac{\left(\beta+b z_{s}\right)(\phi-b c)}{4 b k_{s}-\left(\beta+b z_{s}\right)^{2}-2 \bar{k} b^{2} z_{m}^{2}} \\
& =\frac{\left(\beta+b e_{s}\left(p_{e}+\Delta p_{e 1}\right)\right)\left[\phi-b\left(c+\lambda e_{0}\left(p_{e}+\Delta p_{e 1}\right)\right)\right]}{4 b k_{s}-\left[\beta+b e_{s}\left(p_{e}+\Delta p_{e 1}\right)\right]^{2}-2 \bar{k} b^{2} e_{m}^{2}\left(p_{e}+\Delta p_{e 1}\right)^{2}} .
\end{aligned}
$$

Considering the mixed carbon policy context, we can get the optimal increase in carbon price with tariff $\lambda$ :

$$
\begin{aligned}
& \Delta p_{e 1}^{*} \\
& =\frac{\sqrt{A_{1}^{2}+4 \lambda b z_{0}\left(\beta+b z_{s}\right)\left[\widehat{\tau}_{1}\left(e_{s}^{2}+2 \bar{k} e_{m}^{2}\right)-\lambda e_{s} e_{0}\right]}-A_{1}}{2 b\left[\widehat{\tau}_{1}\left(e_{s}^{2}+2 \bar{k} e_{m}^{2}\right)-\lambda e_{s} e_{0}\right]},
\end{aligned}
$$

where $A_{1}=2 \widehat{\tau}_{1}\left[e_{s}\left(\beta+b z_{s}\right)+2 \bar{k} b e_{m} z_{m}\right]-\lambda\left[e_{0}\left(\beta+b z_{s}\right)+\right.$ $\left.b e_{s} z_{0}\right]+e_{s}(\phi-b c)$ and $\widehat{\tau}_{1}=\left(\beta+b z_{s}\right)(\phi-b c) /\left(4 b k_{s}-(\beta+\right.$ $\left.\left.b z_{s}\right)^{2}-2 \bar{k} b^{2} z_{m}^{2}\right)$ is the initial reduction rate of unit raw material in MSI. $\psi\left(\Delta p_{e 1}^{*}, \lambda\right)$ is the government's optimal mixed carbon policy. 
3.2.2. Model 2: Manufacturer Driven Model. Manufacturer is the leader of the supply chain to coordinate emission reduction. The manufacturer decides retail price and the cooperative efforts to reduce emissions, and then the supplier decides a wholesale price and the reduction rate. We conduct Stackelberg backward induction and take the derivative of $\partial \pi_{s} / \partial w=0, \partial \pi_{s} / \partial \tau=0$ and we get

$$
\begin{aligned}
& w=\frac{\phi-b p+\beta \tau}{b}+c-z_{s}(\lambda+\tau), \\
& \tau=\frac{z_{s}(\phi-b p)+\beta\left(w-c+\lambda z_{s}\right)}{k_{s}-2 \beta z_{s}} .
\end{aligned}
$$

Substituting into (2) and taking the derivative of $\partial \pi_{m} / \partial p=0, \partial \pi_{m} / \partial \mu=0$, the optimal solution is

$$
\begin{aligned}
\mu_{2}^{*} & =\frac{\bar{k} b z_{m}}{\beta+b z_{s}}, \\
\tau_{2}^{*} & =\frac{\left(\beta+b z_{s}\right)\left[\phi-b\left(c+\lambda z_{0}\right)\right]}{4 b k_{s}-2\left(\beta+b z_{s}\right)^{2}-\bar{k} b^{2} z_{m}^{2}}, \\
p_{2}^{*} & \\
= & \frac{\left[\phi-b\left(c+\lambda z_{0}\right)\right]\left[3 b k_{s}-\left(\beta+b z_{s}\right)\left(\beta+2 b z_{s}\right)-\bar{k} b^{2} z_{m}^{2}\right]}{b\left[4 b k_{s}-2\left(\beta+b z_{s}\right)^{2}-\bar{k} b^{2} z_{m}^{2}\right]} \\
& +\left(c+\lambda z_{0}\right), \\
w_{2}^{*} & =\frac{\left[\phi-b\left(c+\lambda z_{0}\right)\right]\left[k_{s}-z_{s}\left(\beta+b z_{s}\right)\right]}{4 b k_{s}-2\left(\beta+b z_{s}\right)^{2}-\bar{k} b^{2} z_{m}^{2}}+\left(c+\lambda z_{s}\right), \\
Q_{2}^{*} & =\frac{b k_{s}\left[\phi-b\left(c+\lambda z_{0}\right)\right]}{4 b k_{s}-2\left(\beta+b z_{s}\right)^{2}-\bar{k} b^{2} z_{m}^{2}} .
\end{aligned}
$$

Similarly, reasonable equation of policy intensity is as follows:

$$
\lambda=\tau_{2}^{*}=\frac{\left(\beta+b z_{s}\right)\left[\phi-b\left(c+\lambda z_{0}\right)\right]}{4 b k_{s}-2\left(\beta+b z_{s}\right)^{2}-\bar{k} b^{2} z_{m}^{2}} .
$$

We can deduce the optimal policy intensity of MSII:

$$
\lambda_{2}^{*}=\frac{\left(\beta+b z_{s}\right)(\phi-b c)}{4 b k_{s}-\left(\beta+b z_{s}\right)\left(2 \beta+b z_{s}-b z_{m}\right)-\bar{k} b^{2} z_{m}^{2}} .
$$

When policy intensity $\lambda \geq \lambda_{2}^{*}$, the corporate fails to finish a given task, and they must pay for the corresponding carbon resource; when policy intensity $\lambda<\lambda_{2}^{*}$, they can accomplish the target with excess carbon quota and get some income through carbon quota trading. Thus, $\left(\lambda-\lambda_{2}^{*}\right)$ is the governmental regulation strategy of carbon policy in MSII.

The supplier's abatement cost subsidy with paid quota mechanism is $\Delta k_{s 2}^{*}=\lambda z_{0} b k_{s} k_{m} /\left(4 k_{m}-b z_{m}^{2}\right) \widehat{Q}_{2}$. For $\lambda e_{s} \widehat{Q}_{2} \bar{P}_{e s 2} \geq \Delta k_{s 2}^{*}$, we get the optimal auction reserve price of supplier with MSII

$$
\bar{p}_{e s 2}^{*}=\left(b k_{s} k_{m}\left(1+e_{m} / e_{s}\right) /\left(4 k_{m}-b z_{m}^{2}\right) \widehat{Q}_{2}^{2}\right) p_{e} \text {; among it }
$$
$\widehat{Q}_{2}=b k_{s}(\phi-b c) /\left(4 b k_{s}-2\left(\beta+b z_{s}\right)^{2}-\bar{k} b^{2} z_{m}^{2}\right)$ is the initial production in MSII with loose carbon policy $(\lambda=0)$.
The optimal abatement cost subsidy of manufacturer is $\Delta k_{m 2}^{*}=\lambda z_{0} k_{m}^{2} /\left(\lambda z_{0} k_{m}+z_{m}^{2} \widehat{Q}_{2}\right)$. For $\lambda e_{m} \widehat{Q}_{2} \bar{p}_{e m 2} \geq \Delta k_{m 2}^{*}$, we get the optimal auction reserve price of manufacturer in MSII:

$$
\bar{p}_{e m 2}^{*}=\frac{k_{m}^{2}\left(1+e_{s} / e_{m}\right)}{\left(\lambda z_{0} k_{m}+z_{m}^{2} \widehat{Q}_{2}\right) \widehat{Q}_{2}} p_{e}
$$

Particularly, when $\lambda=0, \bar{p}_{e m 2}^{*}=\left(\left(1+e_{s} / e_{m}\right) /\left(z_{m} /\right.\right.$ $\left.\left.k_{m}\right)^{2} \widehat{Q}_{2}^{2}\right) p_{e}$.

Similarly, in the context of MSII, we can get the optimal increase in carbon price with tariff $\lambda$ :

$$
\begin{aligned}
& \Delta p_{e 2}^{*} \\
& =\frac{\sqrt{A_{2}^{2}+4 \lambda b z_{0}\left(\beta+b z_{s}\right)\left[\widehat{\tau}_{2}\left(2 e_{s}^{2}+\bar{k} e_{m}^{2}\right)-\lambda e_{s} e_{0}\right]}-A_{2}}{2 b\left[\widehat{\tau}_{2}\left(2 e_{s}^{2}+\bar{k} e_{m}^{2}\right)-\lambda e_{s} e_{0}\right]},
\end{aligned}
$$

where $A_{2}=2 \widehat{\tau}_{2}\left[2 e_{s}\left(\beta+b z_{s}\right)+\bar{k} b e_{m} z_{m}\right]-\lambda\left[e_{0}\left(\beta+b z_{s}\right)+b e_{s} z_{0}\right]+$ $e_{s}(\phi-b c)$ and $\widehat{\tau}_{2}=\left(\beta+b z_{s}\right)(\phi-b c) /\left(4 b k_{s}-2\left(\beta+b z_{s}\right)^{2}-\right.$ $\left.\bar{k} b^{2} z_{m}^{2}\right)$ is the initial reduction rate per unit raw material in MSII. $\psi\left(\Delta p_{e 2}^{*}, \lambda\right)$ is the government's optimal mixed carbon policy.

3.2.3. Model 3: Nash Decision Model. The supplier and manufacturer in the supply chain will take synchronous decisionmaking when their market strength is relatively balanced. Take the derivative of $\partial \pi_{s} / \partial w=0, \partial \pi_{s} / \partial \tau=0, \partial \pi_{m} / \partial p=0$, and $\partial \pi_{m} / \partial \mu=0$. We can get the optimal conditions of the first order as follows:

$$
\begin{aligned}
& \phi-b p+\beta \tau-b\left[w-c+z_{s}(\tau-\lambda)\right]=0, \\
& z_{s}(\phi-b p+\beta \tau)+\beta\left[w-c+z_{s}(\tau-\lambda)\right]-k_{s} \tau=0, \\
& \phi-b p+\beta \tau-b\left[p-w+z_{m}(\mu \tau-\lambda)\right]=0, \\
& \mu z_{m}(\phi-b p+\beta \tau)+\beta\left[p-w+z_{m}(\mu \tau-\lambda)\right] \\
& \quad-\mu^{2} k_{m} \tau=0 .
\end{aligned}
$$

Solve the above equation and we can get the optimal solution of MSIII:

$$
\begin{aligned}
\mu_{3}^{*}= & \frac{\bar{k} b z_{m}}{\beta+b z_{s}}, \\
\tau_{3}^{*}= & \frac{\left(\beta+b z_{s}\right)\left[\phi-b\left(c+\lambda z_{0}\right)\right]}{3 b k_{s}-\left(\beta+b z_{s}\right)^{2}-\bar{k} b^{2} z_{m}^{2}}, \\
p_{3}^{*}= & \frac{\left[\phi-b\left(c+\lambda z_{0}\right)\right]\left[2 k_{s}-z_{s}\left(\beta+b z_{s}\right)-\bar{k} b z_{m}^{2}\right]}{3 b k_{s}-\left(\beta+b z_{s}\right)^{2}-\bar{k} b^{2} z_{m}^{2}} \\
& +\left(c+\lambda z_{0}\right),
\end{aligned}
$$




$$
\begin{aligned}
w_{3}^{*}= & \frac{\left[\phi-b\left(c+\lambda z_{0}\right)\right]\left[k_{s}-z_{s}\left(\beta+b z_{s}\right)\right]}{3 b k_{s}-\left(\beta+b z_{s}\right)^{2}-\bar{k} b^{2} z_{m}^{2}} \\
& +\left(c+\lambda z_{s}\right), \\
Q_{3}^{*}= & \frac{b k_{s}\left[\phi-b\left(c+\lambda z_{0}\right)\right]}{3 b k_{s}-\left(\beta+b z_{s}\right)^{2}-\bar{k} b^{2} z_{m}^{2}} .
\end{aligned}
$$

The reasonable carbon policy is

$$
\lambda=\tau_{3}^{*}=\frac{\left(\beta+b z_{s}\right)\left[\phi-b\left(c+\lambda z_{0}\right)\right]}{3 b k_{s}-\left(\beta+b z_{s}\right)^{2}-\bar{k} b^{2} z_{m}^{2}} .
$$

We can deduce the optimal policy intensity in MSIII

$$
\lambda_{3}^{*}=\frac{\left(\beta+b z_{s}\right)(\phi-b c)}{3 b k_{s}-\left(\beta+b z_{s}\right)\left(\beta-b z_{m}\right)-\bar{k} b^{2} z_{m}^{2}} .
$$

Thus, $\left(\lambda-\lambda_{3}^{*}\right)$ is the governmental regulation strategy of carbon policy with MSIII.

The supplier's abatement cost subsidy of MSIII with paid quota mechanism is $\Delta k_{s 3}^{*}=\lambda z_{0} b k_{s} k_{m} /\left(3 k_{m}-b z_{m}^{2}\right) \widehat{Q}_{3}$. For the income meeting $\lambda e_{s} \widehat{Q}_{3} \bar{p}_{e s 3} \geq \Delta k_{s 3}^{*}$, we get the optimal auction reserve price of supplier in MSIII $\bar{p}_{e s 3}^{*}=\left(b k_{s} k_{m}(1+\right.$ $\left.\left.e_{m} / e_{s}\right) /\left(3 k_{m}-b z_{m}^{2}\right) \widehat{Q}_{3}^{2}\right) p_{e}$, where $\widehat{Q}_{3}=b k_{s}(\phi-b c) /\left(3 b k_{s}-\right.$ $\left.\left(\beta+b z_{s}\right)^{2}-\bar{k} b^{2} z_{m}^{2}\right)$ is the initial production in MSIII with loose carbon policy $(\lambda=0)$.

The optimal abatement cost subsidy of manufacturer is $\Delta k_{m 3}^{*}=\lambda z_{0} k_{m}^{2} /\left(\lambda z_{0} k_{m}+z_{m}^{2} \widehat{Q}_{3}\right)$. For $\lambda e_{m} \widehat{Q}_{3} \bar{p}_{e m 3} \geq \Delta k_{m 3}^{*}$, we get the optimal auction reserve price of manufacturer in MSIII:

$$
\bar{p}_{e m 3}^{*}=\frac{k_{m}^{2}\left(1+e_{s} / e_{m}\right)}{\left(\lambda z_{0} k_{m}+z_{m}^{2} \widehat{Q}_{3}\right) \widehat{Q}_{3}} p_{e} .
$$

Particularly when $\lambda=0, \bar{p}_{e m 3}^{*}=\left(\left(1+e_{s} / e_{m}\right) /\left(z_{m} /\right.\right.$ $\left.\left.k_{m}\right)^{2} \widehat{Q}_{3}^{2}\right) p_{e}$.

Similarly, in the context of MSIII, we can get the optimal increase in carbon price with tariff $\lambda$ :

$$
\begin{aligned}
& \Delta p_{e 3}^{*} \\
& =\frac{\sqrt{A_{3}^{2}+4 \lambda b z_{0}\left(\beta+b z_{s}\right)\left[\widehat{\tau}_{3}\left(e_{s}^{2}+\bar{k} e_{m}^{2}\right)-\lambda e_{s} e_{0}\right]}-A_{3}}{2 b\left[\widehat{\tau}_{3}\left(e_{s}^{2}+\bar{k} e_{m}^{2}\right)-\lambda e_{s} e_{0}\right]},
\end{aligned}
$$

where $A_{3}=2 \widehat{\tau}_{3}\left[e_{s}\left(\beta+b z_{s}\right)+\bar{k} b e_{m} z_{m}\right]-\lambda\left[e_{0}\left(\beta+b z_{s}\right)+b e_{s} z_{0}\right]+$ $e_{s}(\phi-b c)$ and $\widehat{\tau}_{3}=\left(\beta+b z_{s}\right)(\phi-b c) /\left(3 b k_{s}-\left(\beta+b z_{s}\right)^{2}-\right.$ $\left.\bar{k} b^{2} z_{m}^{2}\right)$ is the initial reduction rate per unit raw material in MSII. $\psi\left(\Delta p_{e 3}^{*}, \lambda\right)$ is the government's optimal mixing carbon policy.

\section{Comparative Analysis}

For different supply chain structure, the efficiency of carbon policies may be different. At the same time, we are concerned about the potential impact of consumer preferences of lowcarbon and carbon price on the economic benefits of supply chain and abatement efficiency, which provide reference for decision-making with mixed carbon policies.

Theorem 1. The optimal intensity of carbon policy satisfies $\lambda_{1}^{*}<\lambda_{2}^{*}<\lambda_{3}^{*}$ and is positively correlated with consumer preference $\beta$ and carbon price $p_{e}$.

Theorem 1 shows that in a perfect competitive market with force equality of supplier and manufacturer, the governmental regulation space of carbon policy is the biggest. However, in the supply chain of supplier focus, the governmental regulation space is the smallest. Meanwhile, with increasing environmental awareness of consumers and the maturing carbon market, it will help the government to develop the best carbon policies.

Theorem 2. When $k_{s} \gg \beta \geq 0$, the degree of cooperation satisfies $\mu_{1}^{*} \leq \mu_{2}^{*}=\mu_{3}^{*} \approx\left(z_{m} / k_{m}\right) /\left(z_{s} / k_{s}\right)$. And it is negatively correlated with low-carbon preference $\beta$ and unrelated with the strength of the carbon policy. However, degree of cooperation is positively correlated (unrelated) with carbon price if $\beta>0(\beta=$ $0)$.

Theorem 2 shows that cooperation degree of supply chains depends on the relative "abatement efficiency" of supplier and manufacturer. The higher the abatement efficiency $z_{m} / k_{m}$, the higher the motivation they will have to reduce carbon emission corporately. And under the same condition the more powerful the manufacturer is, the higher the level of cooperation will be. However, contrary to reality phenomena, carbon trading and carbon taxes are invalid on the emissions cooperation of supply chain. Unless consumer preference $\beta$ reaches a certain level, the carbon market can improve cooperation in the supply chain through carbon trading price $p_{e}$. And consumer preference for low-carbon emissions and supply chain cooperation is substitutable: the higher the low-carbon preference, the weaker the cooperation between supplier and manufacturer. This substitution effect is more obvious in the MSI supplier dominated cooperative abatement. The same consumer preference would substitute the cooperation degree of $2 \beta z_{s} /\left(2 k_{m}-b z_{m}^{2}\right) \cdot\left(b z_{m} /\left(\beta+b z_{s}\right)\right)$.

Theorem 3. The realized abatement rate satisfies $\tau_{1}^{*}<\tau_{2}^{*}<$ $\tau_{3}^{*}$. It is negatively correlated with intensity of carbon policy $\lambda$ but positively correlated with consumer preference $\beta$ and carbon trading price $p_{e}(\lambda \rightarrow 0)$.

Theorem 3 shows that perfect competitive carbon market mobilizes the motivation of cooperative abatement. However, the intensity of carbon policy should not be too high; otherwise it will increase the burden on enterprises, leading to lower production rather than improved technology and other means for reducing emissions. It should take advertising, subsidies, and other administrative measures to improve downstream business or consumer acceptance of low-carbon products and use the price mechanism to stimulate enterprises to participate in carbon trading initiative. 
Theorem 4. The retail price satisfies $p_{3}^{*} \leq p_{2}^{*} \leq p_{1}^{*}$; the wholesale price satisfies $w_{2}^{*} \leq w_{3}^{*} \leq w_{1}^{*}$. The retail and wholesale price are positively correlated with intensity of carbon policy $\lambda$ and consumer preference $\beta$ but are negatively correlated with carbon price $p_{e}(\lambda \rightarrow 0)$.

Theorem 4 shows that perfect competitive carbon market can effectively reduce retail prices and increase consumer welfare. In the supplier driven supply chain, consumers would bear the highest retail price, wholesale price, and carbon emission reduction cost. Consumers bear the high cost of carbon emissions. The carbon trading price decline may ease this cost shifting caused by the price, but the driving force of reduction will decline. The higher consumer preference for low-carbon can effectively balance the contradiction between price and abatement costs.

Theorem 5. Product sales meet $Q_{1}^{*} \leq Q_{2}^{*} \leq Q_{3}^{*}$, and they are negatively correlated with the intensity of carbon policy $\lambda$ and positively correlated with consumer preference for low-carbon $\beta\left(\beta \geq b z_{s}\right)$ and the carbon price $p_{e}(\lambda \rightarrow 0)$. If $\beta \leq b z_{s}$ and $\partial Q_{1}^{*} / \partial \beta \leq 0$, sales in MSI and consumer preference for lowcarbon show negative correlation.

Theorem 5 shows that perfect competitive carbon market is more conducive to maintain production capacity and stable social employment. Nevertheless, cooperative abatement of supplier driven or manufacturer driven supply chain will result in reduction of production capacity. And high intensity of carbon policy would frustrate the enterprises' enthusiasm in production. Only increase in market acceptance and market maturity can maintain a reasonable level of production while promoting carbon reduction. In addition, carbon reduction of supplier focus, namely, MSI, is more sensitive to consumer preference for low-carbon and carbon price. Therefore, only when the consumer preference for low-carbon reaches a certain level, can demand reduction effect outweigh cooperative effect, achieving expected carbon reduction target with higher regulatory policy.

\section{Numerical Analysis}

In this section, we present a numerical analysis based on Guangzhou Carbon Emissions Exchange in China. For analysis, the relevant data have been collected from a steel supplier and an appliance manufacturer. We use the method proposed by Wang et al. [24] to measure product carbon emission factor. Assuming that the market capacity $\phi$ is 20 million units, price sensitive coefficient $b=200$, cost of unit raw material $c=150$ yuan, and carbon emissions coefficients $e=2$ ton, carbon emissions reduction cost factor $K=1$ billion yuan, unit carbon quota $P_{e}=30$ yuan, and paid quota proportion was $3.0 \%$. The optimal solutions of the threereduction mode in different market situations are as shown in Table 1.

At present, Chinese carbon trading price is lower than EUETS, UKETS, and so on. The identifying system of lowcarbon products is not perfect and the market lacks consumer awareness of low-carbon products which are in line with
"Scenario 1." The results showed that the optimal carbon policy intensity in MSII and MSI was 2.55\%, 0.45 percent lower than the current carbon policy intensity. And optimal carbon intensity in MSIII policy is 3.40\%, 0.4 percent higher than the current carbon policy intensity. Therefore, if current carbon market is oligopolistic market, the proportion of the quota should be paid down and reduce the intensity of carbon policy. If carbon market is close to a perfect competitive market, the strength of the carbon policy is still some room for upward adjustment. With the rise in consumer preference for low-carbon or carbon prices, floating space of paid quota proportion, carbon tax, and so on would also be expanded.

Cooperation levels of abatement in the three models are close. Scenario 1 and Scenario 3 are $62.50 \%$, while the cooperation level in Scenario 4 and Scenario 2 significantly decreased, which proved that only when the consumer preference reaches a certain level, can the carbon market promote cooperation through the price mechanism. It also indicates that Chinese enterprises have higher motivation to carry out supply chain abatement cooperation. For realized reduction rate, reduction rate in MSIII is the highest $3.40 \%$, 0.85 percent higher than MSI and MSII. And the reduction rates in the three models are consistent with optimal policy intensity, finishing the task of reducing emissions just right. From the perspective of price, MSIII has the lowest retail price of 716.6 yuan per unit of product, nearly 70 yuan lower than the MSI and MSII. However, MSII has the minimum wholesale price of 363.0 yuan per unit, nearly 200 yuan lower than the MSI. Since MSIII had greater price advantage, its production and supply chain profits are the highest among the three modes. Although the perfect competitive carbon market (MSIII) can effectively improve consumer welfare, it is subject to the larger scale of production capacity leading to higher supply chain carbon intensity. Therefore, it is necessary to take other supporting measures like production limit to reduce emissions.

From the perspective of auction reserve price of paid quotas, the current auction reserve price of supplier is about 100 yuan, while the manufacturer is around 50,000 yuan. This indicates that when the manufacturer is involved in the abatement cooperation of supply chain, quotas should be paid for suppliers while manufacturers receive the carbon quotas free. The auction reserve price in MSIII supplier is the lowest 77.5 yuan/ton, 30 yuan lower than the MSI and MSII. Therefore, a perfect competitive market can effectively reduce abatement cost of the supply chain of enterprises, thus improving the efficiency. Finally, the optimal mixed policy in the three models is basically the same, and the optimal mixing carbon policy of MSIII is 0.0794 yuan/ton; that is, corporate would increase the carbon price by 0.0794 yuan/ton to eliminate negative impact caused by 1 yuan/ton of carbon tax.

Figure 1 verifies changes of optimal solutions with the changes of "consumer preference $\beta$ " with current carbon policy. Carbon policy changes in the next three reduction mode hybrid optimal solutions; optimal visible MSIII carbon policy strength, the actual reduction rate, yield, and profits were higher than the other two models, and the reserve price and auction are relatively low, indicating that the carbon market is fully competitive with a higher economic 
TABLE 1: Optimal solution for three supply chain abatement modes with current carbon policy.

\begin{tabular}{|c|c|c|c|c|c|c|c|c|c|c|c|c|}
\hline \multirow[t]{2}{*}{ Analytic indicators } & \multicolumn{3}{|c|}{$\begin{array}{c}\text { Scenario 1: low-carbon } \\
\text { price }+ \text { low } \\
\text { consumer preference }\end{array}$} & \multicolumn{3}{|c|}{$\begin{array}{c}\text { Scenario } 2 \text { : low-carbon } \\
\text { price }+ \text { high } \\
\text { consumer preference }\end{array}$} & \multicolumn{3}{|c|}{$\begin{array}{c}\text { Scenario 3: high } \\
\text { carbon price + low } \\
\text { consumer preference }\end{array}$} & \multicolumn{3}{|c|}{$\begin{array}{c}\text { Scenario } 4 \text { : high } \\
\text { carbon price }+ \text { high } \\
\text { consumer preference }\end{array}$} \\
\hline & MSI & MSII & MSIII & MSI & MSII & MSIII & MSI & MSII & MSIII & MSI & MSII & MSIII \\
\hline $\begin{array}{l}\text { Optimal intensity of } \\
\text { carbon policy }\end{array}$ & $2.55 \%$ & $2.55 \%$ & $3.40 \%$ & $4.69 \%$ & $4.71 \%$ & $6.25 \%$ & $8.51 \%$ & $8.66 \%$ & $11.31 \%$ & $10.69 \%$ & $11.00 \%$ & $14.23 \%$ \\
\hline $\begin{array}{l}\text { Optimal cooperation } \\
\text { level }\end{array}$ & $62.50 \%$ & $62.50 \%$ & $62.50 \%$ & $33.89 \%$ & $34.09 \%$ & $34.09 \%$ & $62.50 \%$ & $62.50 \%$ & $62.50 \%$ & $48.99 \%$ & $50.00 \%$ & $50.00 \%$ \\
\hline $\begin{array}{l}\text { Realized abatement } \\
\text { rate }\end{array}$ & $2.55 \%$ & $2.55 \%$ & $3.40 \%$ & $4.69 \%$ & $4.72 \%$ & $6.27 \%$ & $8.65 \%$ & $8.80 \%$ & $11.59 \%$ & $10.94 \%$ & $11.27 \%$ & $14.72 \%$ \\
\hline $\begin{array}{l}\text { Retail price } \\
\text { (yuan/unit) }\end{array}$ & 787.6 & 787.2 & 716.6 & 789.0 & 787.8 & 718.1 & 783.7 & 779.9 & 710.2 & 786.6 & 780.2 & 713.0 \\
\hline $\begin{array}{l}\text { Wholesale price } \\
\text { (yuan/unit) }\end{array}$ & 574.9 & 363.0 & 433.1 & 575.4 & 363.6 & 433.0 & 568.6 & 358.5 & 422.6 & 569.0 & 358.9 & 420.9 \\
\hline Production & 42488 & 42553 & 56674 & 42413 & 42919 & 56998 & 43261 & 44024 & 57954 & 42885 & 45084 & 58865 \\
\hline $\begin{array}{l}\text { Profit of supplier (ten } \\
\text { thousand yuan) }\end{array}$ & 1801 & 902 & 1600 & 1798 & 910 & 1605 & 1822 & 930 & 1612 & 1805 & 953 & 1624 \\
\hline $\begin{array}{l}\text { Profit of manufacturer } \\
\text { (ten thousand yuan) }\end{array}$ & 902 & 1801 & 1605 & 904 & 1798 & 1623 & 930 & 1822 & 1669 & 932 & 1806 & 1722 \\
\hline $\begin{array}{l}\text { Supply chain profit } \\
\text { (ten thousand yuan) }\end{array}$ & 2703 & 2703 & 3205 & 2702 & 2708 & 3228 & 2752 & 2753 & 3281 & 2738 & 2759 & 3346 \\
\hline $\begin{array}{l}\text { Carbon emission } \\
\text { intensity (ton/ten } \\
\text { thousand yuan) }\end{array}$ & 38.37 & 38.43 & 42.81 & 37.64 & 38.00 & 41.74 & 36.15 & 36.73 & 39.42 & 35.31 & 36.71 & 38.16 \\
\hline $\begin{array}{l}\text { Auction reserve price } \\
\text { of supplier (yuan/ton) }\end{array}$ & 103.4 & 103.0 & 77.5 & 103.1 & 101.3 & 76.6 & 330.2 & 317.8 & 244.8 & 329.2 & 303.0 & 237.3 \\
\hline $\begin{array}{l}\text { Auction reserve price } \\
\text { of manufacturer } \\
\text { (yuan/ton) }\end{array}$ & 51605 & 56477 & 41091 & 51657 & 55949 & 40828 & 35369 & 43820 & 30666 & 35504 & 42513 & 30037 \\
\hline $\begin{array}{l}\text { Optimal mix policy } \\
\text { (yuan/ton) }\end{array}$ & 0.0795 & 0.0792 & 0.0794 & 0.1446 & 0.1430 & 0.1441 & 0.8513 & 0.8225 & 0.8434 & 1.0390 & 0.9823 & 1.0225 \\
\hline
\end{tabular}

Note: intensity of current carbon policy is $\lambda=3.0 \%$; higher and low consumer preference are $\beta=0$ and $\beta=100000$, respectively; high and low-carbon price are $P_{e}=30$ and 100 yuan/quotas.

efficiency and reduces emissions, but because of the larger capacity supply chain carbon emissions lead to excessive growth, thus supporting the need to take other measures to reduce emissions to limit production and so on. At the same time, carbon trading price has stronger effects than the carbon tax, more sensitive to the effects of the supply chain. Figure 2 shows the effect of consumer preference for low-carbon optimal solution under the contemporary carbon policies. It is obvious that all the three models have the same cooperation level for carbon emission reduction and their cooperation level would be increased with the decrease of consumer preference. And with the decline in the rate of carbon intensity, consumer preferences in MSIII are the fastest; the reduction rate will eventually exceed the other two modes and bear the cost of the lowest paid bid. Thus, with increased consumer awareness of environmental protection, low-carbon products are increasingly acknowledged by the market, and the competition market's advantage of carbon cooperation reduction would become more significant.

\section{Conclusion}

This paper established cooperation decision model for a mixed policy of carbon trading-carbon tax (environmental tax) in a two-stage $S$ - $M$ supply chain. For three different cooperative abatement situations, we considered supplier driven model, the manufacturer driven model, and the equilibrium game model. We investigated the influence of mixed policy with constraint of reduction targets on supply chain price, productivity, profits, emissions reduction rate, the best level of cooperation, and the proportion of paid quotas and measured the policy sensitivity of carbon trading policy and consumer preference for low price. The results showed that (1) high-strength carbon policies do not necessarily encourage enterprises to effectively reduce emissions, and increasing market acceptance of low-carbon products or raising the price of carbon can promote the benign reduction; (2) perfect competitive carbon market has a higher efficiency than oligarch carbon market, but their optimal level 

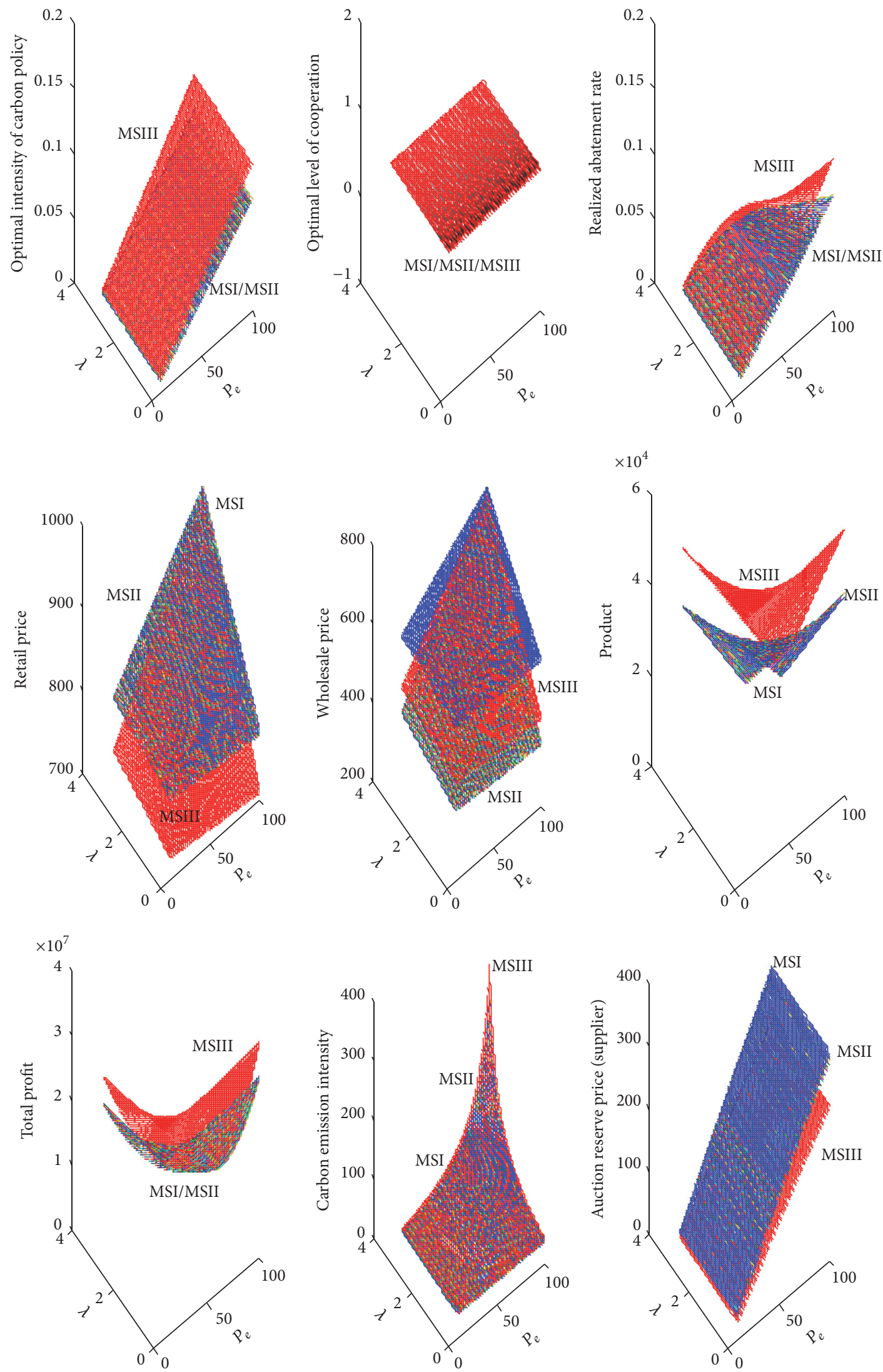

FIGURE 1: Changes of optimal solutions in the three modes with mixed policy. 


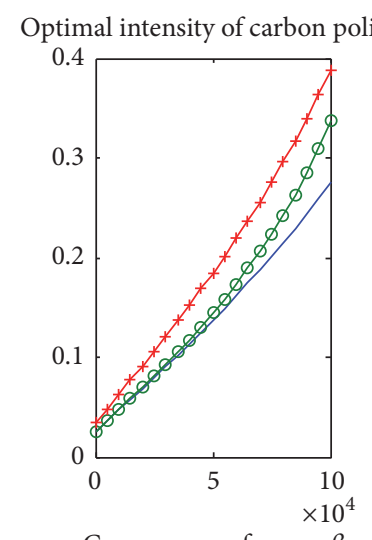

Consumer preference $\beta$

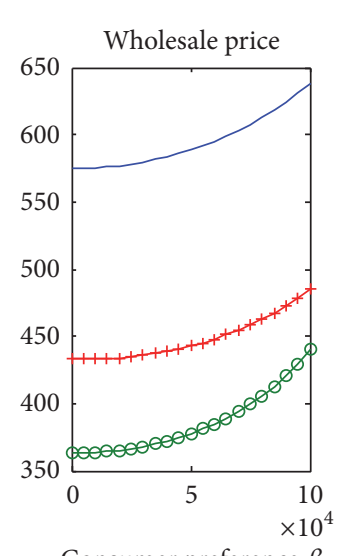

Consumer preference $\beta$

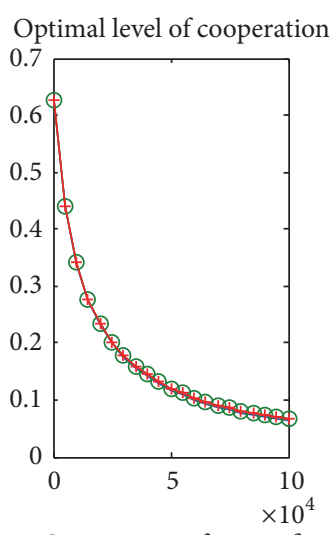

Consumer preference $\beta$

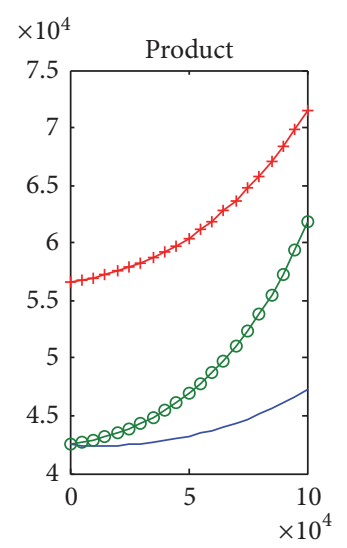

Consumer preference $\beta$

Auction reserve price (supplier)

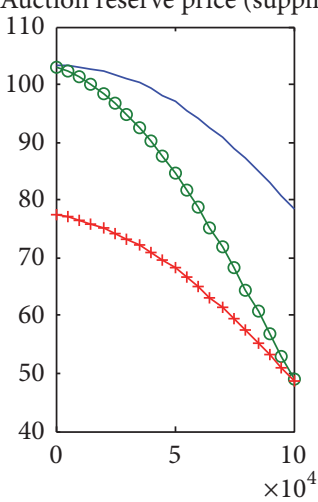

Consumer preference $\beta$

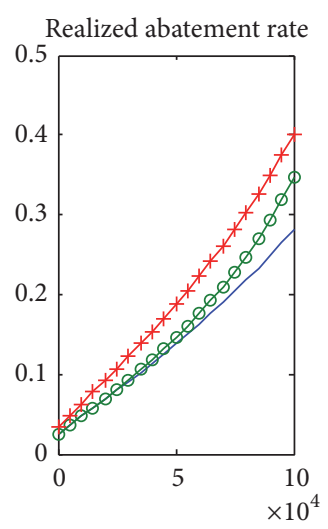

Consumer preference $\beta$

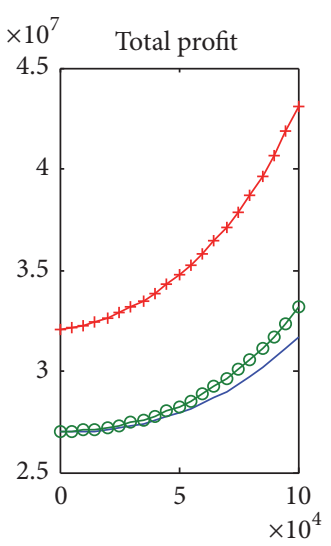

Consumer preference $\beta$

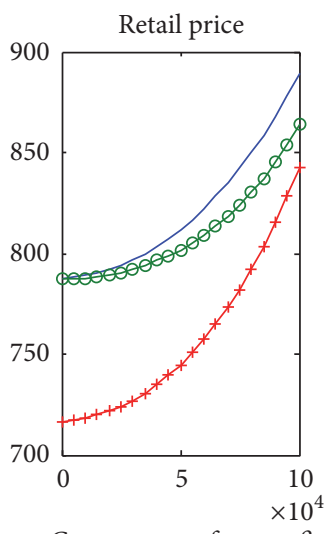

Consumer preference $\beta$

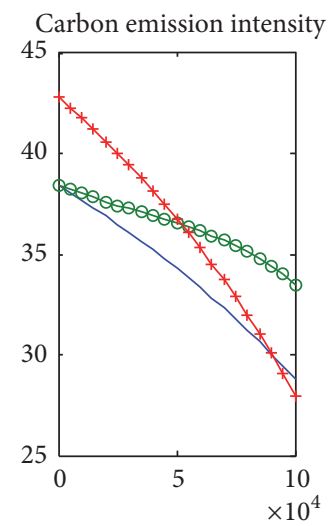

Consumer preference $\beta$

Optimal mix carbon policy $\Delta P_{e}$

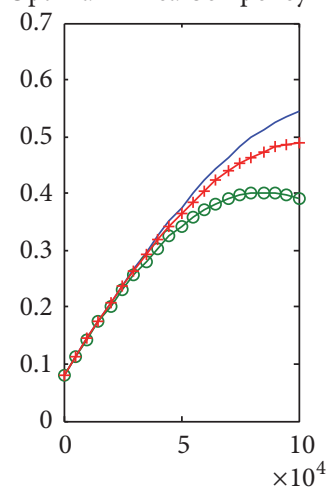

Consumer preference $\beta$

$$
\begin{array}{ll}
- & \text { MSI } \\
- & \text { MSII } \\
+ & \text { MSIII }
\end{array}
$$

Figure 2: Changes of optimal solutions with the changes of "consumer preference $\beta$ " with current carbon policy.

of cooperation is not different with mixed carbon policy; the realized abatement rate is in line with the intensity of carbon policy; (3) the policy sensitivity of the carbon trading mechanism is stronger than the carbon tax; "paid quota mechanism" can subsidize the cost of abatement and improve reduction initiative. Finally, we use a numerical example to solve the optimal decisions under different market situations, validating the effectiveness of model and the conclusions.

This paper believes that China should accelerate the establishment and improvement of the carbon trading market currently, develop a reasonable paid quota proportion and auction reserve price, and keep the carbon market price 
stability. At the same time, carbon tax should be a reduction measure to promote the use of the cost of subsidies and other forms of interenterprise supply chain collaboration to carry out abatement. Furthermore, it should increase supporting and publicity for low-carbon products to raise consumer awareness and expand market share of low-carbon products, thus achieving a low-carbon economy. Future research may consider more practical factors like contract coordination, multicycle, and other factors.

\section{Competing Interests}

The authors declare that they have no competing interests.

\section{Acknowledgments}

This research was supported by NSFC Grants (nos. 71473013, 71132008) and Beijing Wuzi University High-Level Breeding Project (no. GJB20164003).

\section{References}

[1] S. Du, F. Ma, Z. Fu, L. Zhu, and J. Zhang, "Game-theoretic analysis for an emission-dependent supply chain in a 'cap-andtrade’ system," Annals of Operations Research, vol. 228, no. 1, pp. 135-149, 2015.

[2] G. E. Metcalf, "Designing a carbon tax to reduce U.S. greenhouse gas emissions," Review of Environmental Economics and Policy, vol. 3, no. 1, pp. 63-83, 2009.

[3] M. K. Chien and L. H. Shih, "An empirical study of the implementation of green supply chain management practices in the electrical and electronic industry and their relation to organizational performances," International Journal of Environmental Science and Technology, vol. 4, no. 3, pp. 383-394, 2007.

[4] X. P. Xie and D. Z. Zhao, "Research on cooperation strategy of enterprises' carbon emission reduction in low carbon supply chain," Journal of Management Science, vol. 26, no. 3, pp. 108119, 2013.

[5] Q. F. Fu, L. Y. Xin, and S. H. Ma, "Evolutionary game of carbonemission-reduction investment in supply chains under a contract with punishment mechanism," Journal of Management Sciences in China, vol. 19, no. 4, pp. 56-70, 2016.

[6] M. Altmann and R. Bogaschewsky, "An environmentally conscious robust closed-loop supply chain design," Journal of Business Economics, vol. 84, no. 5, pp. 613-637, 2014.

[7] M. Y. Jaber, C. H. Glock, and A. M. A. El Saadany, "Supply chain coordination with emissions reduction incentives," International Journal of Production Research, vol. 51, no. 1, pp. 69-82, 2013.

[8] A. Diabat, T. Abdallah, A. Al-Refaie, D. Svetinovic, and K. Govindan, "Strategic closed-loop facility location problem with carbon market trading," IEEE Transactions on Engineering Management, vol. 60, no. 2, pp. 398-408, 2013.

[9] A. Chaabane, A. Ramudhin, and M. Paquet, "Design of sustainable supply chains under the emission trading scheme," International Journal of Production Economics, vol. 135, no. 1, pp. 37-49, 2012.

[10] I. Kockar, A. J. Conejo, and J. R. McDonald, "Influence of the emissions trading scheme on generation scheduling," International Journal of Electrical Power \& Energy Systems, vol. 31, no. 9, pp. 465-473, 2009.
[11] Y. H. Cheng and Z. K. Xiong, "The optimal emission reduction and pricing strategies and coordination based on the perspective of supply chain under carbon tax policy," Science Research Management, vol. 36, no. 06, pp. 81-91, 2016.

[12] Z. K. Xiong, P. Zhang, and N. Guo, "Impact of carbon tax and consumers' environmental awareness on carbon emissions in supply chains," Systems Engineering-Theory \& Practice, vol. 34, no. 09, pp. 2245-2252, 2014.

[13] C. L. Luo, "Supply chain analysis for electric vehicle under government's subsidy," Management Review, vol. 26, no. 12, pp. 198-205, 2014.

[14] S. Sim, J. Oh, and B. Jeong, "Measuring greenhouse gas emissions for the transportation sector in Korea," Annals of Operations Research, vol. 230, no. 1, pp. 129-151, 2013.

[15] B. Lin and X. Li, "The effect of carbon tax on per capita $\mathrm{CO}_{2}$ emissions," Energy Policy, vol. 39, no. 9, pp. 5137-5146, 2011.

[16] J. Li and Q. Su, "The influence research on the supply chain considering carbon tax," Soft Science, vol. 29, no. 3, pp. 52-59, 2015.

[17] L. Yang, C. S. Zheng, and J. N. Ji, "Misreporting decisions and coordination in supply chain under asymmetric carbon information," Chinese Journal of Management Science, vol. 24, no. 4, pp. 111-120, 2016.

[18] K. M. R. Hoen, T. Tan, J. C. Fransoo, and G. J. Van Houtum, "Effect of carbon emission regulations on transport mode selection under stochastic demand," Flexible Services and Manufacturing Journal, vol. 26, no. 1-2, pp. 170-195, 2014.

[19] L. Yang, C. Zheng, and M. Xu, "Comparisons of low carbon policies in supply chain coordination," Journal of Systems Science and Systems Engineering, vol. 23, no. 3, pp. 342-361, 2014.

[20] N. Gao and S. M. Ryan, "Robust design of a closed-loop supply chain network for uncertain carbon regulations and random product flows," EURO Journal on Transportation and Logistics, vol. 3, no. 01, pp. 5-34, 2014.

[21] T.-M. Choi, "Multi-period risk minimization purchasing models for fashion products with interest rate, budget, and profit target considerations," Annals of Operations Research, vol. 237, no. 1, pp. 77-98, 2016.

[22] J. Song and M. Leng, "Analysis of the single-period problem under carbon emissions policies," International Series in Operations Research \& Management Science, vol. 176, no. 02, pp. 297312, 2012.

[23] S. Benjaafar, Y. Li, and M. Daskin, "Carbon footprint and the management of supply chains: insights from simple models," IEEE Transactions on Automation Science and Engineering, vol. 10, no. 1, pp. 99-116, 2013.

[24] J. K. Wang, Z. F. Liu, H. Bao, and B. Y. Bian, "Research on computing method of carbon emission of home appliances products based on LCA," Journal of Hefei University of Technology, vol. 35, no. 08, pp. 1043-1048, 2012. 


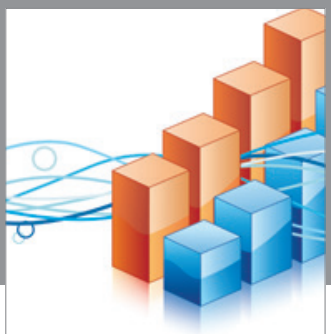

Advances in

Operations Research

vatem alat4

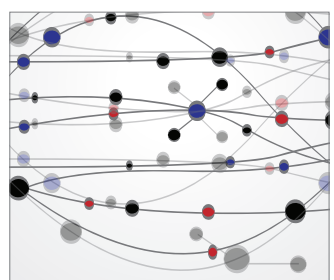

\section{The Scientific} World Journal
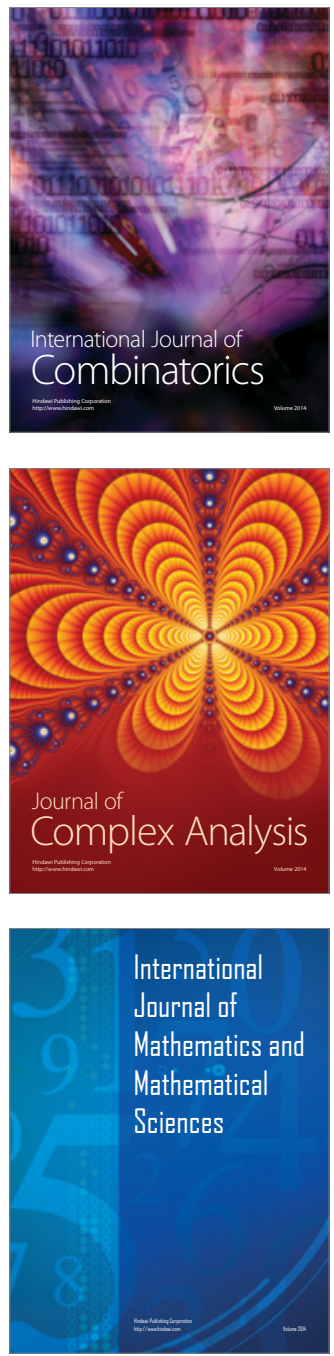
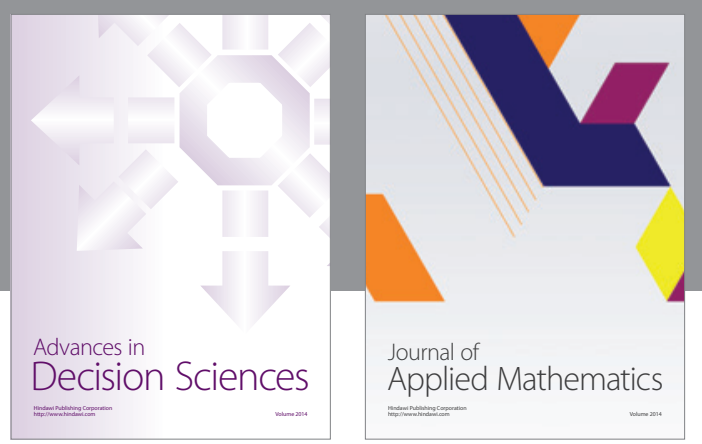

Algebra

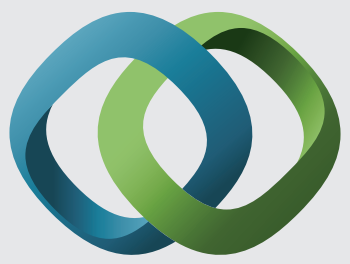

\section{Hindawi}

Submit your manuscripts at

https://www.hindawi.com
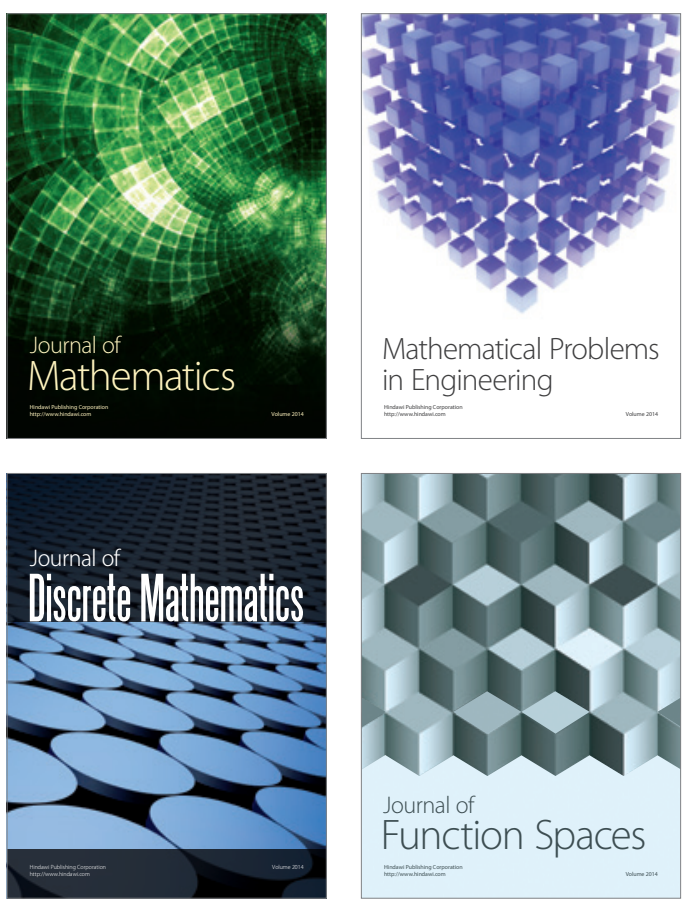

Mathematical Problems in Engineering
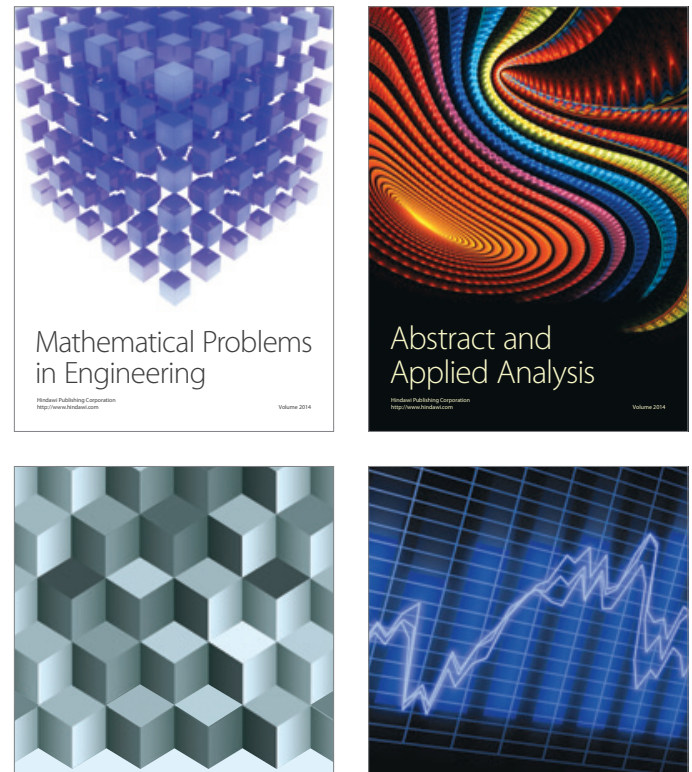

Journal of

Function Spaces

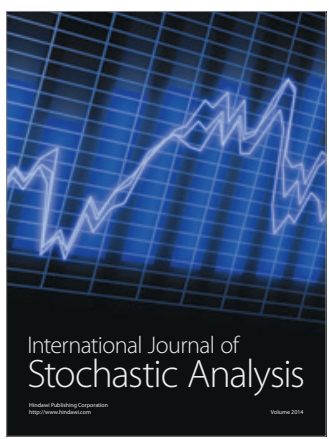

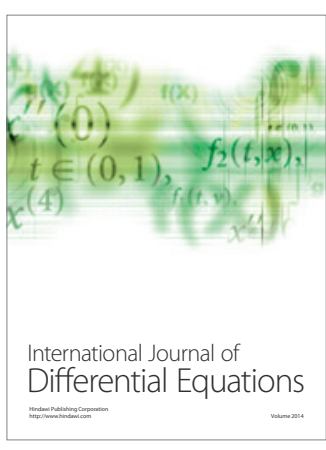
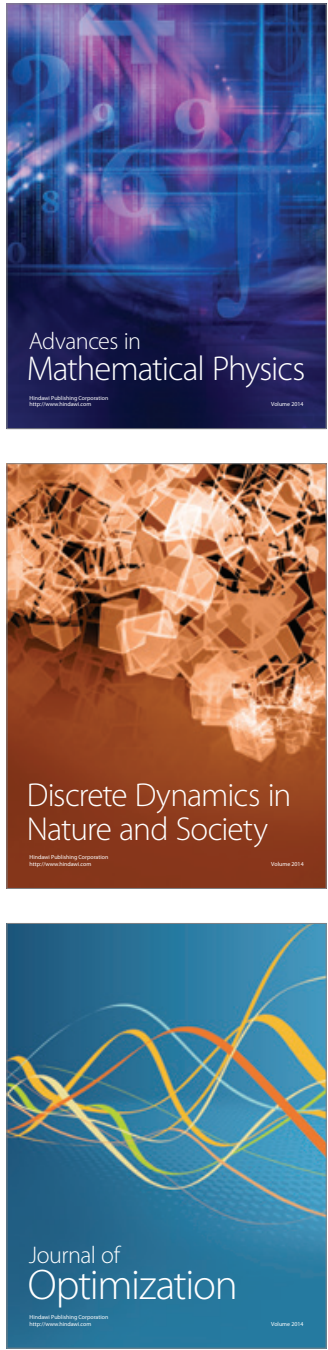